\title{
Intervención educativa sobre virus de inmunodeficiencia humana en la comunidad habitante de calle que asiste a un centro de acogida en la ciudad de Bogotá D.C. - Colombia
}

\author{
Educational intervention on Human Immunodeficiency Virus in the \\ homeless community that attends a reception center in the city of Bogotá \\ D.C. - Colombia
}

Andrés Gabriel Zárate Sanabria ${ }^{1}$, Cristian Nicolás Rodríguez Pava ${ }^{1}$, Myriam Judith Huérfano Torres $M S c^{2}$ Olga Lucia Orjuela López $M S c^{2}$, Alejandro Castaño $M S c^{2}$

\section{Resumen}

Objetivo. Evaluar el impacto de capacitaciones impartidas por estudiantes de la Universidad Colegio Mayor de Cundinamarca (UCMC) referentes al VIH en población habitante de calle asistente a un centro de acogida en la ciudad de Bogotá D.C. Materiales y método. Se realizaron encuestas en las que se definieron los factores socio-demográficos, los hábitos y los conocimientos sobre el VIH de la población. Se examinaron 47 individuos de los cuales el $92 \%$ eran hombres y el $12,78 \%$ de toda la población fue seropositiva para VIH, así mismo, de ésta población el $33,33 \%$ de los individuos no recordaban el número de parejas sexuales que habían tenido en el último ańo. Respecto a las charlas sobre VIH por parte de los estudiantes de la UCMC el 61,40\% las calificaron como buenas. Resultados. Con base en el estudio se pudo evidenciar que en la población habitante de calle es necesaria una intervención educativa, dado que esto reduce el riesgo de infección por VIH y el desarrollo de la enfermedad, a la vez que se puede promover la reintegración social de esta comunidad.

Palabras claves: Habitante de calle, virus de inmunodeficiencia humana, intervención educativa, centro de acogida, salud pública, epidemiología.

\section{Abstract}

HIV is a world problem, according to the World Health Organization 36.7 million people infected by this virus, of which the greatest risk occurs in people who are in a state of neglect, by example the inhabitant street. It is estimated in Bogotá D.C., the inhabitant street population near 9,614 characters. The objective was to evaluate the Impact of training given by students of the Universidad Colegio Mayor de Cundinamarca (UCMC) concerning HIV Population Inhabitants street attending the reception Centre in the City of Bogotá D.C. To collect information conducted surveys that defined the socio-demographic factors, Habits, and Knowledge About HIV population. 47 individuals of which $92 \%$ were men and $12.78 \%$ of the entire population was seropositive HIV, also, of this population they were examined $33.33 \%$ of individuals did not remember the number of sexual partners in the last year. Regarding the talks on HIV by students

1. Bacteriólogo y Laboratorista Clínico, Universidad Colegio Mayor de Cundinamarca.

2. Profesor(a) Facultad de Ciencias de la Salud, Universidad Colegio Mayor de Cundinamarca.3. Docente Investigadora Grupo Bioprocesos y

Control, Universidad Colegio Mayor de Cundinamarca. 
UCMC the $61.40 \%$ rated this as the good. Base with the study itself was evident that's inhabitant street population is required educational intervention, given a this Risk of HIV infection and disease development reduce the time you can promote reintegration this type of social community.

Keywords: Inhabitants of Street, of Human Immunodeficiency Virus, Educational intervention, shelter, Public Health, Epidemiology.

\section{Introducción}

La infección por el virus de inmunodeficiencia humana (VIH) es una problemática mundial. Según la Organización de Naciones Unidas, para el año 2015, 36,7 millones de personas estaban infectadas por este virus de las cuales 2,1 millones de personas contrajeron la infección en el año 2016 y cerca de 1,1 millones de personas fallecieron por causas relacionadas con el SIDA (1). Según estos mismos datos en para el año 2015, en América Latina 2 millones de personas eran seropositivas y se presentaron cerca de 100.000 nuevos casos de infección por el VIH en la región (1).

En Colombia, según ONUSIDA hay 120,000 personas que viven con VIH, de las cuales 4,700 fallecieron por causas relacionadas al SIDA (2). El país presenta una mayor incidencia en hombres que tienen relaciones sexuales con hombres, las mujeres transgénero, y los habitantes de la calle los cuales presentan prevalencias superiores al 5\% (3).

En Colombia no existen datos precisos sobre la población habitante de calle. Se estima que tan solo en Bogotá D.C existen cerca de 9.614 personas en esta situación (4). Según la Secretaria de Integración Social, el habitante de calle es definido como: "persona que no reside de manera permanente en lo que se considera una vivienda prototípica como casa, apartamento o cuarto, por lo menos 30 dias continuos; y de manera estable, al menos 60 días en la misma unidad" (5). En la última encuesta realizada por la Secretaria de Integración Social de Bogotá D.C se estimó que el $56.6 \%$ de la población habitante de calle comenzó a habitar la calle siendo menor de edad y el $44.8 \%$ de los habitantes de la calle de la capital colombiana nacieron en municipios o ciudades diferentes a Bogotá (6).

Se estima que del total de la población habitante de calle en Bogotá D.C el 86.9\% son hombres, el $8.4 \%$ son menores de 18 años, el $17.9 \%$ son jóvenes entre 19 y 25 años, el $38.9 \%$ son adultos entre 26 y 40 años y el 32\%, son adultos mayores (5).

Hay que reconocer que la infección por el VIH es una de las principales causas de vulnerabilidad social (7), con mayor afectación en los poblaciones marginales (8). Debido a esto es claro que la infección por VIH, y la vulnerabilidad social comparten un componente epidemiológico que las relaciona.

La intervención educativa sobre VIH/SIDA es una estrategia útil en los métodos de promoción de la salud y prevención de la enfermedad, por ello la Universidad Colegio Mayor de Cundinamarca a través del programa de Bacteriología y Laboratorio Clínico ha creado vínculos con centros de acogida a la población habitante de calle para intervenir en los métodos de control y tratamiento del VIH/ SIDA (9). Por lo anterior, este estudio pretendió determinar la prevalencia de VIH en relación con las características demográficas y sociales del habitante de calle en la ciudad de Bogotá D.C - Colombia.

\section{Materiales y métodos}

Se realizó un estudio descriptivo transversal, con un enfoque empírico analítico, con el cual se obtuvo información sobre características relacionadas a datos demográficos, sociales, hábitos y prácticas y calidad del conocimiento impartido por parte de 
los estudiantes de octavo semestre del programa de Bacteriología y Laboratorio Clínico de la Universidad Colegio Mayor de Cundinamarca previamente capacitados mediante clases de salud publica y planes de promoción y prevención en salud en los temas relacionados al VIH/SIDA en la población habitante de calle en Bogotá D.C., que asistían a un centro de acogida. Se dieron tres charlas por los estudiantes entre Marzo de 2014 y Mayo de 2014.

Fueron encuestados 47 habitantes de calle en el centro de acogida que asistieron a las charlas educativas dadas por los estudiantes sobre VIH/SIDA.

Los datos obtenidos fueron tabulados y se realizó un cruce de variables según los objetivos del estudio.

\section{Resultados}

Dentro de las variables demográficas se evaluaron la identidad sexual en relación a la orientación sexual (ver Tabla 1). De las 47 personas encuestadas, el $92 \%$ eran hombres entre los que se encontraban homosexuales, transexuales, bisexuales y heterosexuales, siendo este último grupo el más amplio en los hombres. Por otro lado, las mujeres representaron el $8 \%$ de la población encuestada. Dentro de los grupos de edad es notorio que la población con mayor predomino en la calle $(44,68 \%)$ se encuentra entre los 31 y 40 ańos de edad, seguido de los individuos entre 20 y 30 años $(23,4 \%)$ y siendo las edades entre los 41 y 45 ańos la que le sigue $(19,14 \%)$ y los mayores a 46 años es la menos frecuente $(12,76 \%)$.

Tabla 1. Género, identidad sexual y edad de los habitantes del centro de acogida.

\begin{tabular}{|c|c|}
\hline Género,e identidad sexual & $\%$ de individuos \\
\hline \multicolumn{2}{|l|}{$\mathrm{N}=47$} \\
\hline Hombre & $91,4 \%$ \\
\hline Bisexual & $10,6 \%$ \\
\hline Heterosexual & $51,1 \%$ \\
\hline Homosexual & $6,3 \%$ \\
\hline Transexual & $23,4 \%$ \\
\hline
\end{tabular}

\begin{tabular}{|c|c|}
\hline Mujer & $8,6 \%$ \\
\hline Bisexual & $4,3 \%$ \\
\hline Heterosexual & $4,3 \%$ \\
\hline \multicolumn{2}{|c|}{ Grupo de edad } \\
\hline Edad (Años) & $\%$ de individuos \\
\hline $20-30$ & $23,4 \%$ \\
\hline $31-40$ & $44,68 \%$ \\
\hline $41-45$ & $19,14 \%$ \\
\hline$\leq 46$ & $12,76 \%$ \\
\hline
\end{tabular}

Dentro del análisis que se realizó para evaluar el estado de los habitantes de calle que asistían al centro de acogida se realizó una pregunta para conocer el estado de esta población frente a la seropositividad para VIH. Los resultados arrojaron que el 12,78\% de la población eran VIH positivos, todos hombres de diferentes identidades sexuales. El 46,82\% de la población encuestada era negativa para la prueba de VIH, de este el 4,26\% eran mujeres y el restante hombres. El 4,26\% de la población se había realizado el test pero desconocía el resultado de éste. Por último el 36,19\% nunca se había realizado el examen de VIH (ver Tabla 2).

Tabla 2. Relación género e identidad sexual de los habitantes del centro de acogida con el resultado de la prueba VIH/SIDA Bogotá D.C.

\begin{tabular}{|l|r|}
\hline $\begin{array}{c}\text { Resultado de la prueba } \\
\text { segun género,e identidad } \\
\text { sexual }\end{array}$ & \% de individuos \\
\hline \multicolumn{2}{|c|}{$\mathrm{N}=47$} \\
\hline \multicolumn{2}{|c|}{ Hombre } \\
\hline Bisexual & $\mathbf{9 1 , 4 \%}$ \\
\hline Negativo & $\mathbf{1 0 , 6 4 \%}$ \\
\hline No conoce el resultado & $2,13 \%$ \\
\hline No se la ha realizado & $2,13 \%$ \\
\hline Positivo & $2,13 \%$ \\
\hline Heterosexual & $4,26 \%$ \\
\hline Negativo & $\mathbf{5 1 , 0 6 \%}$ \\
\hline No se la ha realizado & $25,53 \%$ \\
\hline Positivo & $21,28 \%$ \\
\hline
\end{tabular}




\begin{tabular}{|c|c|}
\hline Homosexual & $6,38 \%$ \\
\hline Negativo & $2,13 \%$ \\
\hline No se la ha realizado & $4,26 \%$ \\
\hline Transexual & $23,40 \%$ \\
\hline Negativo & $12,77 \%$ \\
\hline No conoce el resultado & $2,13 \%$ \\
\hline No se la ha realizado & $4,26 \%$ \\
\hline Positivo & $4,26 \%$ \\
\hline Mujer & $8,51 \%$ \\
\hline Bisexual & $4,26 \%$ \\
\hline No se la ha realizado & $4,26 \%$ \\
\hline Heterosexual & $4,26 \%$ \\
\hline Negativo & $4,26 \%$ \\
\hline Total general & $100 \%$ \\
\hline
\end{tabular}

Dentro de los resultados obtenidos respecto a los métodos de protección utilizados por la población habitante de calle se encontró que 10,64\% de la población no utiliza el condón en sus relaciones sexuales, el total de esta población son hombres bisexuales, heterosexuales y transexuales. También se resalta que el 51,07\% de la población usaba condón siempre durante sus relaciones sexuales y el restante de la población $(38,29 \%)$ utilizaba este elemento de protección en algunas ocasiones (ver Tabla 3).

Tabla 3. Relación entre el género e identidad sexual con el uso del condón.

\begin{tabular}{|c|c|}
\hline $\begin{array}{l}\text { Población habitante } \\
\text { de calle segun género,e } \\
\text { identidad sexual }\end{array}$ & $\%$ de individuos \\
\hline \multicolumn{2}{|l|}{$\mathrm{N}=47$} \\
\hline Hombre & $91,4 \%$ \\
\hline Bisexual & $10,64 \%$ \\
\hline No & $2,13 \%$ \\
\hline $\mathrm{Si}$ & $8,51 \%$ \\
\hline Heterosexual & $51,06 \%$ \\
\hline Algunas veces & $23,40 \%$ \\
\hline No & $6,38 \%$ \\
\hline $\mathrm{Si}$ & $21,28 \%$ \\
\hline Homosexual & $6,38 \%$ \\
\hline Algunas veces & $4,26 \%$ \\
\hline $\mathrm{Si}$ & $2,13 \%$ \\
\hline
\end{tabular}

\begin{tabular}{|l|r|}
\hline Transexual & $\mathbf{2 3 , 4 0 \%}$ \\
\hline Algunas veces & $6,38 \%$ \\
\hline No & $2,13 \%$ \\
\hline $\mathrm{Si} \quad$ Mujer & $14,89 \%$ \\
\hline \multicolumn{1}{|c|}{$\mathbf{8 , 5 1 \%}$} \\
\hline Bisexual & $4,26 \%$ \\
\hline Algunas veces & $2,13 \%$ \\
\hline $\mathrm{Si}$ & $2,13 \%$ \\
\hline Heterosexual & $4,26 \%$ \\
\hline Algunas veces & $2,13 \%$ \\
\hline Si & $2,13 \%$ \\
\hline & $\mathbf{1 0 0} \%$ \\
\hline
\end{tabular}

Respecto a la población VIH (+) se evaluó el número de compañeros sexuales en el último año, se halló que el 33,33\% de los individuos encuestados no recordaban el número de parejas sexuales que habían tenido. Por otra parte todos habían tenido más de 3 parejas sexuales en último año (ver Tabla 4).

Tabla 4. Número de compañeros sexuales de los individuos VIH positivos del centro de acogida.

\begin{tabular}{|l|r|}
\hline $\begin{array}{c}\text { Número de parejas de } \\
\text { individuos VIH positivos }\end{array}$ & \% de individuos \\
\hline 3 & $16,67 \%$ \\
\hline 4 & $16,67 \%$ \\
\hline 10 & $16,67 \%$ \\
\hline 13 & $16,67 \%$ \\
\hline No recuerda & $33,33 \%$ \\
\hline Total general & $\mathbf{1 0 0 \%}$ \\
\hline
\end{tabular}

Debido a la presencia de población seropositiva para VIH en el centro de acogida, se evaluó la asistencia, control y uso correcto de los medicamentos antiretrovirales. Se encontró que toda la población VIH (+) recibía el tratamiento adecuado, asistía a los controles médicos y cumplía con en tratamiento, de estos el $66,67 \%$ se encontraba como población especial y el restante 33,33\% era régimen subsidiado (ver Tabla 5). 
Tabla 5. Población VIH positivo del centro de acogida en relación con la seguridad social, el tratamiento, control médico y cumplimiento del tratamiento.

\begin{tabular}{|l|l|l|l|l|}
\hline $\begin{array}{l}\text { Régimen de } \\
\text { salud }\end{array}$ & $\begin{array}{l}\text { Personas } \\
\text { VIH } \\
\text { positivo }\end{array}$ & $\begin{array}{l}\text { Recibe } \\
\text { tratamiento }\end{array}$ & $\begin{array}{l}\text { Control } \\
\text { médico }\end{array}$ & $\begin{array}{l}\text { Cumple } \\
\text { con el } \\
\text { tratamiento }\end{array}$ \\
\hline $\begin{array}{l}\text { Población } \\
\text { especial }\end{array}$ & 4 & $66,67 \%$ & $66,67 \%$ & $66,67 \%$ \\
\hline $\begin{array}{l}\text { Régimen } \\
\text { subsidiado }\end{array}$ & 2 & $33,33 \%$ & $33,33 \%$ & $33,33 \%$ \\
\hline $\begin{array}{l}\text { Total } \\
\text { general }\end{array}$ & 6 & $100 \%$ & $100 \%$ & $100 \%$ \\
\hline
\end{tabular}

La evaluación de las charlas dadas por los estudiantes de la Universidad Colegio Mayor de Cundinamarca del programa de Bacteriología y Laboratorio Clínico a la comunidad habitante de calle se evidencia en la Tabla 6. Aquellos que responden como $\mathrm{NO}$ es la población que nunca ha sido capacitada referente al tema de VIH ni por los estudiantes de la UCMC ni por otras instituciones $(19,15 \%)$. Por otra parte, los individuos que se refieren como "otros" son todos aquellos que no han recibido capacitación por parte de los estudiantes de la UCMC pero sí por otras instituciones $(4,26 \%)$. La población que refiere como SI son todos aquellos que han recibido capacitaciones referentes al VIH por parte de los estudiantes de la UCMC (76,23\%) de los cuales el 61,40\% la califican como buena, el 6,32\% como deficiente y un $8,51 \%$ no respondió a este interrogante. En general se observa que la población que asiste a estas charlas impartidas por los estudiantes la consideran buena y los conocimientos impartidos son precisos y concernientes al tema de interés.

Tabla 6. Asistencia y calificación por parte de los habitantes de calle a las capacitaciones propuestas por parte de los estudiantes de la UCMC.

\begin{tabular}{|l|l|}
\hline $\begin{array}{l}\text { Asistencia y calificación } \\
\text { de las capacitaciones }\end{array}$ & $\%$ de individuos \\
\hline No & $\mathbf{1 9 , 1 5 \%}$ \\
\hline Si & $\mathbf{7 6 , 2 3 \%}$ \\
\hline Buena & $61,40 \%$ \\
\hline Deficiente & $6,32 \%$ \\
\hline No responde & $851 \%$ \\
\hline
\end{tabular}

\begin{tabular}{|l|l|}
\hline $\begin{array}{l}\text { Asistió a otras } \\
\text { capacitaciones }\end{array}$ & $4,26 \%$ \\
\hline Total General & $100 \%$ \\
\hline
\end{tabular}

\section{Discusión}

La temática de la violencia en Colombia, ha ido cambiando en los últimos años, una parte de la violencia se ha trasladado a zonas urbanas, creando nuevas formas de desplazamiento (10). En consecuencia, en Colombia y específicamente en Bogotá D.C., existe una amplia progresión de esquemas de desplazamiento, entre ellos: aquel donde individuos, familias o comunidades enteras se ven forzadas a abandonar sus hogares y trasladarse a otras áreas de la misma ciudad (intra-urbano), o tal vez a otros núcleos urbanos (inter-urbano) (11).

La población habitante de calle es un grupo vulnerable frente a la infección por VIH debido a las circunstancias de vida ligadas a su condición de abandono, limitaciones económicas, déficit en los servicios asistenciales y de información en salud, accesibilidad y recursos $(12,13)$. Las relaciones interpersonales que mantienen los habitantes de calle generan factores de riesgo que favorecen la propagación de VIH en esta población $(14,15)$.

Las características demográficas halladas en el presente estudio son similares a las reportadas, donde se establece que hay mayor predominio de hombres habitantes de calle en una edad promedio de 38 ańos (16), la mayor población hallada en el presente estudio fueron hombres $(91,94 \%)$ con una edad entre los 31 y 40 años de edad (44,68\%) (ver Tabla 1). De la población masculina, la más frecuente fue la heterosexual $(51,06 \%)$, seguida por la población transexual $(23,40 \%)$, bisexual con un $10,64 \%$, y por último, la población homosexual con $6,38 \%$. Por otra parte, la población femenina constituyó el 8,51\%, de la cual el 4,26\% eran heterosexuales y el restante $4,26 \%$ eran bisexuales. Por otra parte el aumento de población transexual habitante de calle puede deberse a que este sector de 
la población generalmente cae en la prostitución y posterior abandono en la calle por su situación de rechazo y marginación social.

Un estudio realizado en Medellín donde se relacionó a la población habitante de calle con enfermedades infecciosas como VIH y tuberculosis arrojo que el $17 \%$ de las personas eran seropositivas (17). En dicha investigación se demostró una mayor prevalencia en hombres infectados con VIH $(7,8 \%)$, estos datos concuerdan con los reportados en el presente estudio en donde el 12,78\% del total de encuestados eran VIH (+) de los cuales el $4,26 \%$ eran hombres bisexuales, 4,26\% hombres heterosexuales y el restante $4,26 \%$ eran hombres transexuales (ver Tabla 2).

Dentro de la población VIH seropositiva alarma encontrar que el 33,33\% de los individuos no recuerda con cuántas parejas ha mantenido relaciones sexuales en último año y que en general esta población ha mantenido contacto genital con más de tres personas en último año (ver Tabla 4). Se debe mencionar que todas las personas seropositivas estaban cumpliendo con sus controles médicos y tratamiento, dato que contrasta con lo expuesto en estudios anteriores (18).

Respecto al uso de preservativos en las relaciones sexuales, llama la atención que el 38,29\% de la población encuestada use este mecanismo de protección algunas veces y el 10,64\% no use elementos de protección en sus relaciones sexuales. Este dato puede estar dado ya sea por la falta de información sobre los mecanismos de protección para evitar el contagio del VIH, la falta de dinero para tener acceso a preservativos, negligencia o desinterés, intoxicación por alcohol al momento del contacto sexual, entre otras, esto podría ocasionar un aumento de las cifras de VIH, además que al ser una población flotante la transmisión del virus y la aparición de nuevos casos no es vigilada.

Este tipo de estudios demuestra que la infección por VIH en Colombia se encuentra concentrada en poblaciones con alto grado de vulnerabilidad, exclusión, rechazo y discriminación social como lo indica Agudelo M. et al (19). Ante esto es urgente una intervención mediante los Planes de Promoción en salud y Prevención de la enfermedad (Planes de P y P) para sensibilizar a la población sobre el uso adecuado y continúo del preservativo en sus relaciones sexuales (20).

La prevalencia de VIH hallada en población habitante de calle en Bogotá D.C., representa una alerta en materia de salud pública, y manifiesta la necesidad del desarrollo de planes dirigidos a mitigar el efecto de este virus en esta población mediante estrategias rápidas, eficientes y costo efectivas que permitan prevenir el VIH en este tipo de población (21-24).

\section{Referencias}

1. Organización de las Naciones Unidas. Hoja informativa 2016. ONUSIDA. ONU. New York. 2016.

2. Organización de las Naciones Unidas. Hoja informativa 2016. ONUSIDA. Ministerio de Salud y Protección Social. Colombia. 2016.

3. Organización Mundial de la Salud. Nutrición y VIH/SIDA. Sitio en (http://www.who.int/nutrition/topics/hivaids/es/). Fecha de acceso: 15 de Abril de 2014.

4. Secretaria de Integración Social. Habitantes de calle. Sitio en Internet. 31 marzo de 2014. Consultado en: (http://www. bogota.gov.co/tag/secretaria-de-integraci\%C3\%B3n-social). Fecha de acceso: 15 de Abril de 2015.

5. Alcaldía de Bogotá D.C. "Por medio del cual se establecen lineamientos de política pública para la atención, inclusión y mejoramiento de la calidad de vida del habitante de calle en el Distrito Capital, y se dictan otras disposiciones". Proyecto de acuerdo no. 008 de 2009. Anales del concejo. 2009.

6. Secretaria de Integración Social. Adultez. Sitio en Internet. 16 junio de 201. Consultado en: (http://www.integracionsocial.gov.co/index.php/noticias/98-noticias-adultez/1374-segun-censo-2011-40-habitantes-de-calle-de-bogota-provienen-de-otras-ciudades). Fecha de acceso: 29 de junio de 2016.

7. Correa M. La otra ciudad - Otros sujetos: los habitantes de la calle. Rev Dep Trab Soc Fac Cienc Humanas Univ Nac Colomb. 2007; 9: 37-56.

8. Berbesi-Fernández DYB, Cardona ÁS. Vulnerabilidad al VIH: Revisión sistemática. Investig ANDINA. 2014; 16 (28): 96477. 
9. Rodríguez E, Corrales L. Autoevaluación de las prácticas académicas del programa de Bacteriología y Laboratorio Clínico de la Universidad Colegio Mayor de Cundinamarca. NOVA. 2014; 2 (2): 81-93.

10. González C. Transformación y resiliencia en familias desplazadas por la violencia hacia Bogotá. rev.estud.soc. 2004; 18 : 123-130.

11. Londońo B. Bogotá: una ciudad receptora de migrantes y desplazados con graves carencias en materia de recursos y de institucionalidad para garantizarles sus derechos. Estud Socio Juríd. 2004; 6(1): 353-375.

12. Ministerio de la Protección Social, Fondo de Población de las Naciones Unidas. Factores de vulnerabilidad a la infección por VIH en las mujeres. Bogotá: El Ministerio, unfpa; 2006.

13. Quintero L. La exclusión social en "habitantes de la calle" en Bogotá. Una mirada desde la bioética. Revista colombiana de bioética. 2008; 3(1): 101-144.

14. Ministerio de la Protección Social, Fondo de Población de las Naciones Unidas. Vulnerabilidad a la infección por VIH en personas en situación de calle en las ciudades de Bucaramanga y Barranquilla. Bogotá: El Ministerio, unfpa. 2011.

15. Cortés G, Campuzano S, Turriago A. Erradicación de la pobreza y calidad en la salud: elementos indispensables para alcanzar la cohesión social en Colombia. NOVA. 2013; 11 (20): 97-119.

16. Kushel M, Vittinghoff E, Haas J. Factors associated with the health care utilization of homeless persons. JAMA. 2001; 285(2): 200-206.

17. Correa M, Orozco M, Uribe M, Barraza T, Zapata A, Villa C, et al. Habitantes de la calle y tuberculosis: Una realidad social en Medellín. rev. eleuthera. 2012; (6):101-126.

18. Berbesi D, Martínez A, Segura A, Montoya LP. VIH en habitantes de calle de Medellín. Rev. Fac. Nac. Salud Pública. 2012; 30(3): 310-314

19. Agudelo M, Álvarez M, Correa M, Correa N, Estrada P, Franco J. Tuberculosis en población indigente de Medellín: análisis de los patrones de transmisión de Mycobacterium tuberculosis y su asociación con trastornos mentales y factores psicosociales: informe de investigación. Medellín. CIB.2008.

20. Largo B, Duque L, Realpe C, Escobar G. Utilización del programa de promoción y prevención en las entidades promotoras de salud (EPS) y administradoras del régimen subsidiado (ARS) de Manizales 2001-2002. Colombia Médica. 2002; 33(3):103-107.

21. Noble A, Valencia N, Ortega J. La proyección social: una estrategia para la formación integral en el programa de Bacteriología de la Universidad de Córdoba - Colombia. NOVA. 2012; (10) 18: 237-244.

22. León F. Bioética de la atención de enfermería al enfermo terminal. NOVA. 2003; (1) 1: 24-31.

23. Nausa, J. G. Evaluación Clínica y radiográfica de injertos biocerámicos tipo Hidroxiapatita como alternativa en la reconstrucción de alveolos dentarios postexodoncia. NOVA. 2014; 12(22).
24. Flórez, R. A. N. Avances y perspectivas en Síndrome de Asperger. 2014; Nova, 12(21). 